Research Article

\title{
Impact of Financial Development and Its Spatial Spillover Effect on Green Total Factor Productivity: Evidence from 30 Provinces in China
}

\author{
Junhao Zhong and Tinghui Li $\mathbb{D}$ \\ School of Economics and Statistics, Guangzhou University, Guangzhou 510006, China \\ Correspondence should be addressed to Tinghui Li; lith@gzhu.edu.cn
}

Received 5 July 2019; Accepted 30 August 2019; Published 21 January 2020

Guest Editor: Filipe J. Marques

Copyright (C) 2020 Junhao Zhong and Tinghui Li. This is an open access article distributed under the Creative Commons Attribution License, which permits unrestricted use, distribution, and reproduction in any medium, provided the original work is properly cited.

\begin{abstract}
The relationship between financial development and green economic growth has received much attention in recent years. Research on the relationship between financial development and green total factor productivity (GTFP) is of great importance to China and other countries. This study has attempted to reveal the spatial distribution of China's provincial GTFP and impact of financial development on GTFP by using the method of GML index based on SBM-DDF and the spatial Durbin model (SDM) during the period 1996-2015. Innovation is added to the SDM to reflect the influencing mechanism of financial development on GTFP. The empirical results show the following: (1) The mean of China's provincial GTFP showed a U-shaped curve in 1996-2015. (2) China's provincial financial development promotes the growth of GTFP through innovation channel. The reason is that financial development boosts eco-friendly innovation and the introduction of energy saving technology, leading to a decrease in energy consumption and pollutant emissions. (3) Increasing the level of financial development in the surrounding areas will restrain local GTFP. Our results provide new evidence that China's regional financial development has a spatial spillover effect. (4) China's provincial GTFP has a significant spatial positive correlation. Finally, several policy implications can be summarized to China's 30 provinces.
\end{abstract}

\section{Introduction}

China has experienced rapid economic growth in recent decades, coupled with the issue of high pollution and high emissions. It has achieved significant economic growth, becoming the world's second largest economy, but this growth depends on resource inputs, which create significant pollutant emissions [1]. The extent of haze in China has aroused international and domestic concerns about China's resource and environment problems [2]. Nowadays, financial support for economic restructuring, upgrading, and green economy development have risen to China's national strategy such as "Green Credit Guidelines." The great interest for policymakers, financial institutions, and investors is to manage the process of financial development in such a way that it promotes environmental sustainability. But the existing literature rarely considers environmental issues when discussing the relationship between financial development and economic growth. The nexus of financial development and green total factor productivity (GTFP) is a key to balancing economic development mode transformation and development quality improvement, and further empirical study is necessary.

Nevertheless, in the mainstream literature on the socalled "finance-growth nexus," the issue of the impact of the financial development on GTFP has virtually been neglected. Financial development contributes to GTFP improvement by reducing the financing costs for enterprises, as well as through investing in eco-friendly innovation activities. 
Furthermore, to the best of our knowledge, we infer that the spatial spillover effects of regional financial development will reduce GTFP in the neighboring areas. Existing research has shown that the financial sector is more willing to aggregate and develop, including some financial auxiliary industries such as accounting, insurance actuarial, risk assessment, and legal consulting [3]. Once an area forms a financial agglomeration area, it will inevitably produce a more significant competitive advantage, plunder the credit resources in the adjacent regions, and weaken the ability of finance serving real economy in the neighboring areas [4]. Financial center cities develop more innovative industries and transfer high-energy and high-pollution industries to the less developed neighboring areas [5-7]. This influencing mechanism appropriately explains that financial development in the region is not conducive to the promotion of GTFP in the neighboring areas.

This study attempts to evaluate China's provincial GTFP from 1996 to 2015 and examines the relationship between regional financial development and GTFP. The main contributions of this study are as follows: first, the analysis of the impact of financial development on economic growth considering the quality of environment is in its infancy, and the research in this paper expands this field. Second, this paper introduces innovation into the study of the relationship between financial development and GTFP, providing evidence for the impact of financial development on GTFP through innovative channel. Third, we utilize the spatial Durbin model to analyse the spatial spillover effects of financial development, which is very beneficial to provide policy implications. The inferences made from this study may not only be helpful for policymakers in the financial center cities but may also provide a clearer picture of 30 provinces in China and may assist in comprehending the scenario from a broader and more inclusive regional angle.

The rest of this paper is organized as follows: Section 2 provides a literature review of financial development and GTFP. Section 3 measures China's provincial GTFP. In Section 4, we report the spatial Durbin model and its empirical results. Conclusions are drawn and discussed in Section 5.

\section{Literature Review}

Previous research has initially examined the influential factors of the GTFP $[8,9]$, but little empirical research is conducted to test the impact of financial development on the GTFP. Existing literature-involved GTFP influencing factors mainly focus on environmental regulation, foreign investment, and technology. An important theory for the relationship between environmental regulation and productivity is the Porter hypothesis. The Porter hypothesis posits that rather than simply adding to cost, properly crafted environmental standards can trigger innovation offsets, allowing companies to improve their resource productivity in the long term [10]. Moreover, Li and $\mathrm{Wu}[11]$ argue that the effect of local environmental regulation on green total factor productivity is significantly positive in the developed city and provincial capitals, but negative in the central and west city. Hu et al. [12] examined the spillover effects of labor-based and capital-based foreign direct investment (FDI) on GTFP and found that capital-based FDI has a significant positive spillover effect. Considering the technology, Chen et al. [13] discussed the impact of two types of technologies, technology importation, and independent research, on GTFP. The results show that strengthening the ability of industrial independent $R \& D$ can improve the GTFP obviously but the driving effect of technology importation on industrial green growth is weak. When studying the influencing factors of GTFP, financial development only acts as a control variable in the regression model and is not specifically analysed. For example, Li and $\mathrm{Wu}$ [11] found that the impact of financial development on GTFP is negative in some developed cities and coastal open cities, positive in the western city, and insignificant in most regions.

In fact, financial development contributes to GTFP improvement by reducing the financing costs for enterprises, as well as through investing in eco-friendly innovation activities. On the one hand, financial development helps enterprises reduce financing costs, expand financing channels, and have more funds to invest in new equipment and new projects [14, 15]. Financial intermediations in well-developed financial markets effectively solve the problem of information asymmetry and provide low-cost funds. As a result, companies can enjoy low-cost funding to update technology and invest in environmental projects $[16,17]$. On the other hand, financial development boosts eco-friendly innovation and the introduction of energy saving technology, leading to a decrease in energy consumption and pollutant emissions. Financial development can reduce energy usage due to more energy-efficient technologies [18]. Considering the impact of financial development on environmental degradation, Chinese scholar provides evidence that financial development is helpful to improve the water quality. In addition, previous literature also examines the long run equilibrium relationship between China's financial development and waste gas emissions and finds that financial development has led to a decrease in waste gas emissions [19]. Financial development possesses technical effect and structural effect, which can reduce waste gas emissions. The financing costs reduced are difficult to measure accurately through limited data. Based on this, our research only focuses on the innovation channel when examining the impact of financial development on GTFP.

Financial development and GTFP have a complex relationship, and innovation channel between these two variables plays an important role. The nexus of financial development-innovation-GTFP can clearly be explained in the following three aspects. First, they did not reach a consensus conclusion studying the impact of financial development on the environment. In the existing 
literature, Jalil and Feridun [19] investigated the impact of financial development on environmental pollution and suggested that financial development in China has led to a decrease in environmental pollution. On the contrary, Farhani and Ozturk [20] examined the causal relationship between waste gas emissions, energy consumption, and financial development in Tunisia and showed that financial development has taken place at the expense of environmental pollution. In addition, Dogan and Turkekul [21] suggested that no causality is determined between waste gas, gas emissions, and financial development. Second, many researchers provide a lot of evidence that financial development has promoted the innovative technologies. King and Levine [22] produced document evidence that in a well-functioning financial system, the financial intermediaries may also boost the rate of technological innovation. Mahalik et al. [23] theoretically argued that the role of financial development is important because financial sector development can improve economic efficiency of a country's financial system and quality institutions as well as enhance the innovations. Third, innovation provides endogenous power for GTFP improvement. Chen and Golley [24] suggested that $\mathrm{R} \& \mathrm{D}$ expenditure has a large impact on GTFP growth, confirming that technological capacity impacts positively on productivity growth. Liu et al. [25] further evidenced that technological progress caused by innovation is the main driver of green TFP from the technology-contribution view.

In the context of regional financial development, the idea of the spatial spillover effect of financial development is also worth mentioning. There is a lot of evidence that financial development has radiation and spillover effects. For instance, Ye et al. [26] researched on the spatial spillover effect of financial agglomeration and indicate that financial agglomeration has a positive effect on economic urbanization level but insignificant effect on population urbanization level. Liao et al. [27] studied on the spatial effect of Internet finance and suggested that developing Internet finance can promote the efficiency and technological progress of regional financial resource allocation and can enhance efficiency and technological progress in the allocation of financial resources in the neighboring areas. Zhu et al. [28] investigated spatial spillover effect of financial inclusion development and suggested that regional financial inclusion development has a structural disadvantage and negative spatial spillover effects from the eastern and western regions to the central regions. Yu et al. [29] studied the spatial relationship between financial functions and financial development, and the empirical results indicate that there is a spatial competition effect on financial development.

This study attempted to discover whether China's GTFP would continue to grow under current financial development status. The existing research has done extensive work on financial development, innovation, and GTFP. However, there are few existing attempts to combine the three, especially when studying GTFP. This study thus attempted to expand the existing literature in the following ways. First, this study discusses China's provincial GTFP and it determines from a financial development perspective and attempts to establish an economic growth model that minimizes environmental damage under the regional financial development. Second, this study demonstrates that the innovation channel acts as an important mediator between financial development and GTFP. Third, in the current state of the art, testing the effect of financial development on GTFP through considering spatial effects is a novel contribution in the literature of finance-growth nexus.

\section{Measuring China's Provincial GTFP}

3.1. GML Index Based on SBM-DDF. The common measurement of GTFP included the Solow residual method, stochastic frontier analysis, and data envelopment analysis (DEA). Building on the ideas of Farrell, the seminal work by Charnes et al. [30] applied linear programming to estimate an empirical production technology frontier for the first time. Since then, there have been a large number of books and journal articles written on DEA or applying DEA on various problems of productivity efficiency. This study employs a cutting-edge global Malmquist-Luenberger (GML) index based on directional slacks-based measure (SBM-DDF) to measure GTFP. In contrast, the GML index based on SBM-DDF can both effectively deal with radial and oriented problems and achieve global comparability in the production frontier [31].

A province $K$ is represented as $D M U_{K}$, and it uses $N$ inputs: $x=\left(x_{1}, \ldots, x_{n}\right) \in R_{N}^{+}$and produces $M$ desirable outputs: $y=\left(y_{1}, \ldots, y_{n}\right) \in R_{M}^{+}$and $I$ undesirable outputs: $b=\left(b_{1}, \ldots, b_{n}\right) \in R_{I}^{+}$. Oh [32] constructed the global production possibilities set $P^{\mathrm{G}}(x)$, emphasising the consistency and comparability of the production frontier:

$$
\begin{aligned}
P^{\mathrm{G}}(x)= & \left\{\left(y^{t}, b^{t}\right): \sum_{t=1}^{T} \sum_{k=1}^{K} z_{k}^{t} y_{k m}^{t} \geq y_{k m}^{t},\right. \\
& \forall m ; \sum_{t=1}^{T} \sum_{k=1}^{K} z_{k}^{t} b_{k i}^{t}=b_{k i}^{t}, \forall i ; \sum_{t=1}^{T} \sum_{k=1}^{K} z_{k}^{t} x_{k n}^{t} \leq x_{k n}^{t}, \\
& \left.\forall n ; \sum_{t=1}^{T} \sum_{k=1}^{K} z_{k}^{t}=1, z_{k}^{t} \geq 0, \forall k,\right\}
\end{aligned}
$$

where $z_{k}^{t}$ denotes the weight of each cross section. If $z_{k}^{t} \geq 0$ indicates constant returns to scale.

Drawing on the research of Fukuyama and Weber [33] and Liu and Xin [31], this study defines the global SBM-DDF that covers undesired outputs as 


$$
\begin{aligned}
& \vec{S}_{v}^{G}\left(x^{t, k^{\prime}}, y^{t, k^{\prime}}, b^{t, k^{\prime}}, g^{x}, g^{y}, g^{b}\right) \\
& =\max _{s^{x}, s^{y}, s^{b}} \frac{(1 / N) \sum_{n=1}^{N} s_{n}^{x} / g_{n}^{x}+(1 / M+I)\left(\sum_{m=1}^{M} s_{m}^{x} / g_{m}^{x}+\sum_{i=1}^{I} s_{i}^{b} / g_{i}^{b}\right)}{2} \\
& \text { s.t. } \begin{cases}\sum_{t=1}^{T} \sum_{k=1}^{K} z_{k}^{t} x_{k n}^{t}+s_{n}^{x}=x_{k^{\prime} n}^{t}, \quad \forall n ; \\
\sum_{t=1}^{T} \sum_{k=1}^{T} z_{k}^{t} y_{k m}^{t}-s_{m}^{y}=y_{k^{\prime} m}^{t}, \quad \forall m ; \\
\sum_{t=1}^{K} \sum_{k=1}^{K} z_{k}^{t} b_{k i}^{t}+s_{i}^{b}=b_{k^{\prime} i}^{t}, \quad \forall i ; \\
\sum_{k=1}^{K} z_{k}^{t}=1, z_{k}^{t} \geq 0, & \forall k ; \\
s_{i}^{b} \geq 0, & \forall i,\end{cases}
\end{aligned}
$$

where $\left(g^{x}, g^{y}, g^{b}\right)$ denotes the direction vectors for decreasing inputs, increasing desirable outputs and decreasing undesirable outputs, respectively, and $\left(s_{n}^{x}, s_{m}^{y}, s_{i}^{b}\right)$ denotes the slack vectors for redundant inputs, inadequate desirable outputs, and redundant undesirable outputs, respectively. If the value is greater than 0 , the actual inputs and undesirable outputs are greater than the boundary inputs and outputs, while the desirable outputs are less than the boundary outputs.

With reference to the study of Oh [32], this study constructs a GML index based on SBM-DDF, which can also be derived as the technical efficiency change index GEC and the technological progress change index GTC. GEC refers to the improvement of management systems and resource allocation methods. GTC mainly refers to the improvement of production technologies and manufacturing skills. The details are as follows:

$$
\mathrm{GML}_{t}^{t+1}=\frac{1+\vec{S}_{v}^{\mathrm{G}}\left(x^{t}, y^{t}, b^{t}, g^{x}, g^{y}, g^{b}\right)}{1+\vec{S}_{v}^{\mathrm{G}}\left(x^{t+1}, y^{t+1}, b^{t+1}, g^{x}, g^{y}, g^{b}\right)},
$$

where $\vec{S}_{v}^{\mathrm{G}}\left(x^{t}, y^{t}, b^{t}, g^{x}, g^{y}, g^{b}\right)$ represent the global SBMDDF based on nonoriented measurements. The GML index denotes the change from period $t+1$ to period $t$. If the index is greater than 1 , it represents GTFP growth. If it is less than 1 , it represents GTFP decline. If it is equal to 1, the GTFP is in a stable state.

3.2. Index Selection and Data Source. This study measures GTFP in China's 30 provinces. The data for the GML index based on SBM-DDF includes inputs (i.e., main factor inputs, including capital, labor, and energy) and outputs (including the total production value of the local area with desirable and undesirable outputs). What is more, the inputs and outputs of each industry are quite different. But in fact, it is impossible for us to incorporate all these inputs and outputs into empirical models, and the selection of input and output variables in the existing literature is various [34]. The inputs and outputs in our study are specified as follows:

(1) Labor input: the number of employed persons at the year end is taken as a labor input index, where a unit is 10,000 persons. Data on the labor of China's 30 provinces during 1995-2015 were collected from EPS macro database.

(2) Capital input: capital input is measured by capital stock using the perpetual inventory method. The basic equation is $K_{i t}=\left(1-\delta_{i}\right) K_{i(t-1)}+I_{i t}$, in which $K_{i t}$ is the real capital stock in area $i$ at period $t, I_{i t}$ is the quantity of fixed asset investment, and $\delta_{i}$ represents the depreciation rate of the capital stock. Due to the partial lack of data from the Chinese provinces, we refer to the study of Zhang [35] to estimate the capital stock of the Chinese provinces. The basic year is set in 1995. Corresponding data for 19952015 come from EPS macro database.

(3) Energy input: the total energy consumptions of every province from 1995 to 2015 use the equivalent energy consumption after the standard coal method conversion where the unit is 10,000 ton of standard coal equivalent (tce). Corresponding data for 1995-2015 come from EPS macro database.

(4) Desirable output: to ensure the continuity and comparability of GDP, it is converted into the 1995 base period. The unit is 100 million yuan. Corresponding data for 1995-2015 come from China Statistical Yearbook.

(5) Undesirable output: undesirable outputs generally have three forms: waste water, waste gas, and solid waste. But provincial industrial waste solid emission data were largely missing, and it was excluded from this study. This study uses total industrial waste water discharge to characterise waste water, $\mathrm{SO}_{2}$, and smoke (powder) dust emissions to characterise waste gas. The 
unit of waste water is 10000 tons, and the unit of waste gas is 100 million cube meters. Corresponding data for 1995-2015 come from China Environment Yearbook.

The current research objective did not include an empirical analysis of Tibet, Hong Kong, Macao, or Taiwan because of the special endowment and data availability. Relevant data from 1995 to 2015 were selected using the China Statistical Yearbook, China Environment Yearbook, and EPS macro database. Descriptive statistics of the input and output data are shown in Table 1.

3.3. Provincial GTFP in China. This study used the MaxDEA software to calculate the GML index based on SBM-DDF in 30 Chinese provinces. The GML index is not the GTFP but rather the change rate of the GTFP. Thus, a regression treatment is needed. Suppose that all GTFPs in 1995 were 1. Then, the GTFP in 1996 would be the GTFP in 1995 multiplied by the GML index: $\mathrm{GTFP}_{1996}=\mathrm{GTFP}_{1995} \times$ GML $_{1995-1996}$. The GTFP of other years can be calculated similarly. The results of China's provincial GTFP are presented in Supplementary Table A1.

From Supplementary Table A1, we can observe the spatial and temporal changes in China's provincial GTFP from 1996 to 2015. Based on this result, several conclusions can be drawn. First of all, the mean of China's provincial GTFP showed a U-shaped curve. This indicates that China's GTFP experienced a process of falling first and then rising. In 1996, the mean of China's provincial GTFP was 0.997. Subsequently, GTFP experienced a long-term decline. By 2005, China's provincial GTFP fell to 0.966 . The reason is that China's industry developed heavy and chemical industry at the beginning of this century. This development model has led to a deterioration in the contradiction between China's economic development and environment protection. Moreover, environmental regulations have not been put in place, and the performance of energy conservation and emission reduction has been declining year by year. As a result, the development model directly led to a decline in GTFP year after year and GTFP reached its lowest point in 2005. After 2005, the introduction of a new industrialization road and the implementation of a series of policies on energy conservation and emission reduction guided the transformation of China's economic growth model. Therefore, the provincial GTFP gradually and steadily recovered after a short adjustment. After 2011, "Green Credit Guidelines," "Financial Support for Green Economy Development," and other environmental protection policies in China have improved the company's green innovation capabilities [36, 37]. China's provincial GTFP has grown steadily since 2011.

Furthermore, China's provincial GTFP has gradually become polarized in the past two decades. For instance, in 1996, the Chinese province GTFP ranged from 0.9 to 1.0. Twenty years later, Beijing's GTFP was 1.551, while Guangxi was only 0.662 . The eastern coastal provinces such as Beijing, Tianjin, and Shanghai maintain a high GTFP, while most of the central regions have been at a low level. This is to say that the regional disparity represented by the eastern region, the central region, and the western region is very prominent. This is in line with the current imbalance in China's regional economic development. High-tech industries are developed in coastal developed areas, while high-pollution and high-energy industries are transferred to the central and western regions. There is a huge gap between the provinces in China due to the total waste water discharge and waste gas emissions, which reflects a greater difference in GTFP.

In the end, the provinces with excellent performance in GTFP also show high levels of GTFP in neighboring provinces. For example, Beijing, Shanghai, and their neighboring provinces, e.g., Tianjin and Jiangsu, have higher GTFP. This implies that China's regional GTFP has a positive correlation. As we expected, China's provincial GTFP has spatial autocorrelation. The reason maybe is that the improvement of a province's GTFP has a spillover effect of green innovation technology on neighboring provinces.

\section{Impact of Financial Development on the GTFP}

4.1. Spatial Durbin Model. By taking the spatial impact into consideration, the spatial Durbin model (SDM) can better reflect the spatial impacts of financial development on GTFP. With reference to Elhorst [38], the SDM in this article can be written as follows:

$$
\mathrm{GTFP}=\alpha+\rho \sum_{j=1}^{N} W_{i j} \mathrm{GTFP}_{j i}+X_{i t} \beta+\theta \sum_{j=1}^{N} W_{i j} X_{j i}+\varepsilon_{i t},
$$

where $W_{i j}$ represent the normalized spatial weight matrix. $X_{i j}$ represent financial development, innovation, and control variables. $\sum_{j=1}^{N} W_{i j} \mathrm{GTFP}_{j i}$ denotes the spatial lag terms of GTFP, while $\sum_{j=1}^{N} W_{i j} X_{j i}$ represents the spatial lag term of financial development and control variables.

Before the model parameters are estimated, we need to set the spatial weight matrix. There are three standards in establishing the spatial weight matrix: neighboring spatial weight matrix, distance spatial weight matrix, and economic spatial distance weight matrix. In this study, some of the sample provinces are nonneighboring, but they are apt to be affected by neighboring and nonbordering provinces. Therefore, neighboring and economic spatial distance weight matrix is abandoned. Thus, the reciprocal of geographical distance of provincial capital between different provinces is as the basic element to construct the spatial weight matrix. Following Feng and Wang [8], the specific form of the matrix is as follows:

$$
W_{i j}=\left\{\begin{array}{c}
\frac{1}{d_{i j}^{2},} \quad i \neq j, \\
0, \quad i=j,
\end{array}\right.
$$

where $d_{i j}^{2}$ is the straight-line distance of provincial capital between provinces $i$ and $j$, and it can be calculated by the longitude and latitude coordinates of the central position of each provincial capital. The longitude and latitude 
TABLE 1: Descriptive statistics of variables.

\begin{tabular}{|c|c|c|c|c|c|c|c|c|}
\hline Models & & Variable & Unit & Obs. & Mean & Std. dev. & Min. & Max. \\
\hline \multirow{6}{*}{$\begin{array}{l}\text { GML index based } \\
\text { on SBM-DDF }\end{array}$} & \multirow{3}{*}{ Input } & Labor & 10000 persons & 630 & 2409.412 & 1610.738 & 240.6 & 6636 \\
\hline & & Capital & 100 million yuan & 630 & 16358.58 & 19524.31 & 367.3643 & 120714.7 \\
\hline & & Energy & 10,000 tce & 630 & 9097.704 & 7158.771 & 302.75 & 38899.25 \\
\hline & Desired output & GDP & 100 million yuan & 630 & 6903.367 & 7837.775 & 167.7983 & 49849.92 \\
\hline & \multirow{2}{*}{ Undesirable output } & Waste water & 10000 tons & 630 & 11427.68 & 12065.15 & 182 & 79121.3 \\
\hline & & Waste gas & 100 million cube meters & 630 & 72491.2 & 58812.98 & 3453 & 296318 \\
\hline \multirow{6}{*}{ Spatial Durbin model } & \multirow{6}{*}{-} & GTFP & - & 600 & 0.9821 & 0.1235 & 0.6419 & 1.5513 \\
\hline & & $\mathrm{FD}$ & - & 600 & 1.1038 & 0.3599 & 0.5372 & 2.5847 \\
\hline & & INN & - & 600 & 14896.36 & 34738.48 & 43 & 269944 \\
\hline & & FDI & $\%$ & 600 & 2.7781 & 2.715 & 0.0673 & 16.8423 \\
\hline & & DGDP & Yuan & 600 & 16783.45 & 13948.17 & 1961.124 & 84375.76 \\
\hline & & DENS & Person $/ \mathrm{km}^{2}$ & 600 & 1981.962 & 1374.748 & 5 & 6307.376 \\
\hline
\end{tabular}

coordinates of cities are sourced from National Geographic Information System of China.

\subsection{Financial Development Measurement and Control Var-} iable Selection. To investigate the drivers of GTFP growth across 30 provinces, following previous studies, and within constraints on the available data, financial development and innovation as the mainly explaining variable and the several control variables have been employed in our spatial econometric models.

In measuring financial development, different indicators are also suited to different countries depending on whether the country features a financial system oriented on banks or on the stock market $[39,40]$. The way China establishes and reforms the financial system is completely different from that of developed countries. Banks have always played a leading and even monopoly role. Stock markets, small bonds, and insurance markets have little impact on investment and capital allocation efficiency. Therefore, to measure Chinese financial development, especially of different regions, emphasis should be placed on indicators related to the scale and efficiency of the banking system. Thus, we focus on two indicators to measure financial development of different regions.

The existing literature widely uses financial scale and financial efficiency to measure the level of financial development. In the early time, financial interrelation ratio and the ratio of M2 to GDP are used to measure the scale of China's financial development [40]. However, China's financial system is bank dominated and the development time of stock and bond market that are under the control of state-related policies is short, and it is difficult to divide them by province. Therefore, the ratio of total deposit and loan to nominal GDP is used as an alternative variable to measure financial scale. Initially, the ratio of private sector loans to nominal GDP is often used to measure efficiency of China's financial development. But there are a lot of policy-based lending and nonperforming loans in China. Most of the credit is allocated to the inefficient stateowned enterprises. And the credit extended by the financial sectors to the nonstate-owned enterprises is often more marketable and efficient. Thus, the ratio of nonstate credit to nominal GDP is widely used to measure financial efficiency.

The ratio of nonstate-owned credit to nominal GDP in China can be calculated as expressed in equation (6). It is assumed that the share of state-owned enterprise loans in total loans and the proportion of fixed assets investment in state-owned enterprises in the fixed asset investment of the whole society are fixed ratio $\beta$ :

$$
\begin{aligned}
\frac{\text { total credit }}{\mathrm{GDP}} & =\frac{\mathrm{SOE} \text { credit }}{\mathrm{GDP}}+\frac{\mathrm{NSOE} \text { credit }}{\mathrm{GDP}} \\
& =\left(\frac{\text { total credit }}{\mathrm{GDP}} \times \frac{\mathrm{SOE} \text { credit }}{\text { total credit }}\right)+\frac{\mathrm{NSOE} \text { credit }}{\mathrm{GDP}} \\
& =\beta \times \frac{\text { total credit }}{\mathrm{GDP}} \times \frac{\mathrm{SOE} \text { invest }}{\text { total invest }}+\frac{\mathrm{NSOE} \text { credit }}{\mathrm{GDP}},
\end{aligned}
$$

where SOE and NSOE represent state-owned enterprise and nonstate-owned enterprise and invest indicates the fixed assets investment. Next, we use the fixed-effects model to estimate equation (7) based on the relevant statistics data of China Statistical Yearbook and China Financial Yearbook from 1996 to 2015:

$$
\operatorname{loan}_{i t}=\beta \times\left(\operatorname{loan}_{i t} \times \operatorname{soe}_{i t}\right)+\lambda_{i}+\varepsilon_{i t},
$$

where $i$ represents the province; $\operatorname{loan}_{i t}$ is the ratio of total credit to nominal GDP in province $i$ in year $t(t=1996,2001, \ldots, 2015)$; dummy variable $\lambda_{i}$ and random error term $\varepsilon_{i t}$ are used to express the ratio of nonstate credit to nominal GDP. $\lambda_{i}$ is used to control the influence of various factors that do not change with time but change with the province.

In estimating the regression coefficients, we use the AR (1) process to adjust the sequence-related problems of random interference terms and the result is shown as follows:

$$
\begin{aligned}
\operatorname{loân}_{i t} & =\underset{(0.0231)}{0.9003}+\underset{(0.0489)}{0.4561} \times\left(\operatorname{loan}_{i t} \times \text { soe }_{i t}\right), \\
\widehat{\rho} & =0.8769 .
\end{aligned}
$$

0.9003 is the arithmetic mean value of fixed effect estimation in 30 provinces; 0.8760 indicates the estimated value of the first-order correlation coefficient of random error term; and the standard errors of estimated coefficients are in brackets. Therefore, the ratio of nonstate credit to nominal GDP can be calculated as expressed in the following equation: 


$$
\begin{aligned}
\frac{\text { NSOE credit }}{\text { GDP }}= & \frac{\text { total credit }}{\text { GDP }}-0.4561 \times \frac{\text { total credit }}{\text { GDP }} \\
& \times \frac{\text { SOE invest }}{\text { total invest }} .
\end{aligned}
$$

After obtaining the ratio of nonstate credit to nominal GDP measuring the financial efficiency, we use two variables, financial scale and financial efficiency, to define the level of financial development (FD). Financial scale and financial efficiency are converted into a standardized sequence with zero mean and fixed variances. Then, these two variables are added by equal weight to obtain China's provincial financial development index.

This study uses patent applications rather than R\&D input to reflect the regional innovation capacity (INN). As pointed out by Pan et al. [42], the information of patent grants has been covered in patent applications and pendency from patent applications to grant is necessary, and patent grants cannot truly reflect the current level of technological innovation. In this study, the number of patent applications in each province is chosen as the index of provincial innovation capacity.

In addition to our key variables of interest, we introduce several important control variables into our models. The control variable $X_{i t}$ added to the model includes foreign direct investment (FDI), GDP per capita (DGDP), and population density (DENS) [1, 43]. FDI is expressed using the ratio of foreign direct investment to the total provincial production value. According to the "pollution heaven" hypothesis, local governments may lower environmental standards to attract FDI, which may lead to diversified competition, and underdeveloped areas may be inclined to reduce environmental standards, while developed areas usually choose to improve environmental standards. To determine whether the environmental Kuznets curve exists for economic development level and GTFP, GDP per capita is used. The DGDP of each province has deflated by the deflator of GDP per capita, and its basic year is set in 1995 . On the one hand, high population quality becomes a form of external supervision on environmental pollution and, on the other hand, a high population quality improves GTFP. If DENS is too high, the environment is overloaded and its selfcleaning ability declines. The data for the above variables come from the EPS database, and the missing information is obtained from the China Statistical Yearbook for the various years. Descriptive statistics of the data used in SDM are shown in Table 1.

4.3. Empirical Analysis. In the investigation of spatial dependence, the global Moran's I values of provincial GTFP is 0.131 . These results refute the original assumption at $1 \%$ significance. This result shows that the level of GTFP in China's provinces has an obvious spatial effect on the regional distribution. GTFP is not completely randomly distributed, as provinces with higher levels of GTFP are surrounded by other provinces in the high value, whereas provinces with lower levels are also surrounded by other provinces in the low value. There are obvious geographical agglomeration features.
TABLE 2: Results of Wald and LR tests.

\begin{tabular}{lcc}
\hline Test & Statistic & $p$ value \\
\hline Wald lag & 23.487 & $1.258 e-06$ \\
LR lag & 43.052 & $5.329 e-11$ \\
Wald error & 41.783 & $1.02 e-10$ \\
LR error & 46.272 & $1.029 e-11$ \\
\hline
\end{tabular}

Furthermore, the likelihood-ratio (LR) and Wald test are used to judge whether the SDM can be simplified to the spatial lag model (SLM) or the spatial error model (SEM). The test results (Table 2) show that the Wald lag value and the LR lag value are 23.487 and 43.052, respectively. The results reject the null hypothesis that the coefficient of the spatial term is zero at the $1 \%$ level. At the same time, the Wald error value and the LR error value are 41.783 and 46.272 , respectively. The results also reject the null hypothesis that the coefficient of the spatial term is zero at the $1 \%$ level. This shows that the SDN is more suitable for China's provincial GTFP. According to the Hausman test, this study selects the fixed effect model (test statistic is 62.024 , and $p$ value is $5.945 e-11)$.

The model (3) in Table 3 shows the parameter estimation of the impact of financial development on GTFP. The results show that the influential coefficient of financial development on GTFP is positive (0.0082), but not significant. This result is very close to the result of $\mathrm{Li}$ and $\mathrm{Wu}[11]$, which found that the impact of financial development on GTFP is negative in some developed cities and coastal open cities, positive in the western city, and insignificant in most regions. Based on the influencing mechanism of financial development we mentioned above, we conclude that financial development cannot directly act on GTFP. We construct SDMs (1) and (2) to examine the mediating effects of innovation channel on the finance-growth nexus. The parameter estimation results are shown in Table 3.

China's provincial financial development promotes the growth of GTFP through the innovation channel. Firstly, the results of Model (1) in Table 3 show that financial development (FD) has a positive impact on GTFP (0.0434) and the coefficient is significant at the $10 \%$ level. Secondly, when examining the relationship between FD and innovation (INN), like Model (2) results show, we find that FD has a positive impact on INN (0.1429), and the coefficient is significant at the $1 \%$ level. Finally, the INN term is added to the regression and shown in Model (3). The influence coefficient (0.0082) of FD in Model (3) is smaller than the influence coefficient (0.0434) of FD Model (1), and the influence coefficient is not significant. The impact coefficient of innovation on GTFP is positive (0.3227) and is significant at $1 \%$. The goodness of fit of Model (3) is greater than that of Model ( 1 ) ( $R$ square: $0.8326>0.8199)$. The results show that innovation is a mediator of the relationship between financial development and GTFP. This means that China's regional finance supports the development of a green economy. Financial development does not directly affect GTFP but indirectly improves GTFP by increasing the level of innovation. Financial intermediaries and financial markets convert funds into capital through various financing mechanisms, meet the 
TABLE 3: SDM regression results of the impact of financial development on green total factor productivity.

\begin{tabular}{lccc}
\hline Dependent variable & $(1)$ & $(2)$ & $(3)$ \\
& GTFP & INN & $0.0082(0.3286)$ \\
FD & $0.0434^{*}(1.7969)$ & $0.1429^{* * *}(9.015)$ & $0.3227^{* * *}(5.0769)$ \\
INN & & & $-0.0185^{*}(-1.6735)$ \\
FDI & $-0.0325^{* * *}(-2.8835)$ & $-0.0303^{* * *}(-4.1165)$ & $-0.9538^{* * *}(-4.155)$ \\
DGDP & $-0.8796^{* * *}(-3.8618)$ & $0.9514^{* * *}(6.4016)$ & $-0.0858^{* * *}(-3.1341)$ \\
DENS & $-0.0685^{* *}(-2.4371)$ & $0.0027(0.1502)$ & $0.0208(0.4026)$ \\
$W \times$ FD & $-0.1131^{* *}(-2.5112)$ & $0.0273(0.8833)$ & $-0.7159^{* * *}(-5.8849)$ \\
$W \times$ INN & & $0.4833^{* * *}(11.2488)$ & $0.2720^{* * *}(5.3922)$ \\
$W \times$ GTFP & $0.2700^{* * *}(5.3083)$ & & 0.8326 \\
$R$ square & 0.8199 & 0.9830 & 0.1107 \\
Sigma & 0.1191 & 0.0514 & -170.8221 \\
Log likelihood & -192.8546 & 46.3365 & - \\
\hline
\end{tabular}

$*^{* * *}$, and ${ }^{* * *}$ indicate significance at the $10 \%, 5 \%$, and $1 \%$ levels, respectively.

capital needs of enterprises, and support enterprises in technology research and innovation activities, thereby reducing energy consumption and carbon dioxide emissions. Although financial development can bring more capital elements to enterprises, if companies do not convert the loans they receive into technological innovations, they will not effectively improve GTFP.

Increasing the level of financial development in the surrounding areas will restrain local GTFP. At first, the results of Model (1) show that the financial development in the surrounding area $(W \times \mathrm{FD})$ has a negative impact on GTFP $(-0.1131)$ and is significant at the $5 \%$ level. Next, as shown in Model (2), the impact of $W \times$ FD on innovation in surrounding areas $(W \times I N N)$ is equivalent to the impact of FD on INN. This is to say that the impact of $W \times \mathrm{FD}$ on $W \times$ INN is the positive impact (0.1429) and is significant at the $1 \%$ level. At last, the Model (3) results show that the impacts of $W \times \mathrm{FD}$ and $W \times$ INN on the GTFP are 0.0208 and -0.7159 , but the coefficient of $W \times \mathrm{FD}$ is insignificant. The results show that innovation is also a mediator of the financial development of the surrounding areas and local GTFP. Financial development in the surrounding areas has inhibited local GTFP through the innovation channel. The result is consistent with the study of Mahmood et al. [5], who examined the environmental effects of financial market development (FDM) on the $\mathrm{CO}_{2}$ emissions in six East Asian countries and found that neighboring countries' FMD showed a positive effect on the local $\mathrm{CO}_{2}$ emissions. Our results also provide new evidence that financial development has a spatial spillover effect. The reason is that once a financial agglomeration zone is formed in the surrounding areas, it will inevitably produce a more significant competitive advantage, plunder the region's economic resources and production factors, and weaken the ability of finance serving real economy in the neighboring areas [4]. The development of financial markets has brought together financial institutions in central cities, driving high-tech innovative industries of central cities, but transferring highenergy and high-pollution industries to surrounding areas. Therefore, financial development in the surrounding areas will reduce local GTFP.

China's provincial GTFP has a significant spatial positive correlation. According to the results of Models (1) and (3), the coefficient of $W \times$ GTFP is close to 0.27 and is significant at the $1 \%$ level. This is consistent with the results of Moran's I value. For provinces with high GTFP, GTFP in the surrounding areas is often high. Therefore, these results are somewhat consistent with those of Wang et al. [44] and Sornette et al. [45], who found that China's regional GTFP has an agglomeration effect. The improvement of provincial GTFP will lead to an increase in overall regional production efficiency. In addition, the spatial spillover effect of GTFP has narrowed the unbalanced development of China's regional economy.

\section{Conclusions and Implications}

This study has attempted to reveal the spatial distribution of China's provincial GTFP and impact of financial development on GTFP during the period 1996-2015. China has achieved tremendous economic growth in the past two decades and has become the world's second largest economy. The relationship between financial development and green economic growth has received much attention in recent years. Research on the relationship between financial development and GTFP is of great importance to China and other countries. By using the method of GML index based on SBM-DDF, this study constructs a comprehensive green total factor productivity (GTFP) of 30 provinces in China to measure China's "Green" productivity growth. Furthermore, an empirical analysis of financial development affecting provincial GTFP has taken into consideration the spatial spillover effect. Innovation as a mediator variable is added to the spatial Durbin model (SDM) to reflect the influencing mechanism of financial development on GTFP.

The evaluation of China's provincial GTFP has enabled us to arrive at a range of important findings. The several findings are as follows: (1) The mean of China's provincial GTFP showed a U-shaped curve in 1996-2015. This indicates that China's GTFP experienced a process of falling first and then rising. The reason is that China's high pollution and high investment development model at the beginning of this century has led to environmental degradation. However, the introduction of a new industrialization road and the implementation of a series of energy saving emission reduction policies led to the transformation of China's economic growth 
model. China vigorously promoted environmental protection and green economy policies, and GTFP grew steadily since 2011. (2) China's provincial GTFP has gradually become polarized in the past two decades. The regional differences represented by the eastern, central, and western regions are very prominent. High-tech industries are developed in coastal developed areas, and high-pollution and high-energy industries are transferred to the central and western regions. Due to the large gap in waste water exhaust emissions, the provincial GTFP is polarized. (3) The provinces with excellent performance in GTFP also show high levels of GTFP in neighboring provinces. For example, Beijing, Shanghai, and their neighboring provinces, e.g., Tianjin and Jiangsu, have higher GTFP. (4) This implies that China's regional GTFP has a positive correlation. The reason maybe that the improvement of a province's GTFP has a spillover effect of green innovation technology on neighboring provinces.

By applying the SDM, the impact of financial development on GTFP was investigated to interpret the important determinant factors of China's provincial GTFP from 1996 to 2015. The empirical results show the following: (1) China's provincial financial development promotes the growth of GTFP through innovation channel. This regression result of SDM indicates that China's regional finance supports the development of a green economy. Financial development does not directly affect GTFP but indirectly improves GTFP by increasing the level of innovation. The reason is that financial development boosts eco-friendly innovation and the introduction of energy saving technology, leading to a decrease in energy consumption and pollutant emissions. (2) Increasing the level of financial development in the surrounding areas will restrain local GTFP. Our results provide new evidence that China's regional financial development has a spatial spillover effect. The development of financial markets has brought together financial institutions in central cities, driving high-tech innovative industries of central cities, but transferring high-energy and high-pollution industries to surrounding areas. Therefore, financial development in the surrounding areas will reduce local GTFP. (3) China's provincial GTFP has a significant spatial positive correlation. The high-quality GTFP brings advanced green production technology to the surrounding area to improve GTFP.

(1) Regard regional spatial association as an important decision-making variable for regional coordinated development: it should also increase the closeness of the relationship in different provinces and create more spatial spillover channels as important decisionmaking goals. Furthermore, according to the different status and role of each region in spatial association and the different functions of the economic growth sector, the government has formulated targeted regional development policies. Orientate regulation and precise regulation are introduced to enhance the spatial synergy of regional economic growth.

(2) Improve the quality of financial development though financial scale and financial efficiency: it will alleviate the financing constraints of China's real economy, especially the financing constraints of nonstate- owned enterprises. The government should vigorously promote green credit and other policies to improve industrial structure, transformation and upgrading, and green economy development.

(3) Emphasise technological innovation and encourage technological innovation activities of private enterprises: enterprises rationally use capital to promote technological innovation to enhance GTFP. The government should increase its R\&D investment and encourage enterprises, universities, and other R\&D institutions to do the same. In addition, investment structure of innovation should remain rational, avoiding resource redundancy. In particular, future policies should transfer more R\&D investment to basic research.

(4) Amplify the radiation effect of financial agglomeration: the development of provincial GTFP is characterized by a significant polarization effect. Developed regions such as Beijing, Tianjin, and Shanghai have established hierarchical financial partnerships with surrounding areas. This can effectively strengthen interregional cooperation, carry out the differentiated competition, and improve the balanced development of the regional financial sector. The government needs to vigorously support the structural upgrading of rural, central, and western financial institutions, to narrow the differences in China's regional economic development.

This paper has several limitations and can be expanded by further research in plenty of ways. First, this study analyses the impact of financial development on provincial GTFP; however, different financial industries have various effect because of the industrial heterogeneity. So further research can distinguish the impacts of banking, securities, and insurance on GTFP. Second, due to the data limitation, this study does not further analyse the impact of financial development on the GTFP of other countries. Cases from other countries also need to be studied and compared with China. Therefore, further research could expand on the perspectives of advanced economies or developing economies, evaluate their GTFP development, and estimate the impact of financial development on GTFP.

\section{Data Availability}

The data used to support the findings of this study are included within the article.

\section{Conflicts of Interest}

The authors declare that they have no conflicts of interest.

\section{Supplementary Materials}

In this study, we employ a global Malmquist-Luenberger (GML) index based on directional slacks-based measure (SBM-DDF) to measure green total factor productivity (GTFP). We used the MaxDEA software to calculate the 
GML index based on SBM-DDF in 30 Chinese provinces. Based on the results of GML index, all GTFPs in 1995 were 1. Then, the GTFP in 1996 would be the GTFP in 1995 multiplied by the GML index. The GTFP of other years can be calculated similarly. The results of China's provincial GTFP are presented in Table A1 of Appendix A. (Supplementary Materials)

\section{References}

[1] M. Song, J. Du, and K. H. Tan, "Impact of fiscal decentralization on green total factor productivity," International Journal of Production Economics, vol. 205, pp. 359-367, 2018.

[2] C. Feng and M. Wang, "The heterogeneity of China's pathways to economic growth, energy conservation and climate mitigation," Journal of Cleaner Production, vol. 228, pp. 594-605, 2019.

[3] I. Moosa, L. Li, and R. Jiang, "Determinants of the status of an international financial centre," The World Economy, vol. 39, no. 12, pp. 2074-2096, 2016.

[4] C. Wang, X. Zhang, P. Ghadimi, Q. Liu, M. K. Lim, and H. E. Stanley, "The impact of regional financial development on economic growth in Beijing-Tianjin-Hebei region: a spatial econometric analysis," Physica A: Statistical Mechanics and Its Applications, vol. 521, pp. 635-648, 2019.

[5] H. Mahmood, M. Furqan, and O. Bagais, "Environmental accounting of financial development and foreign investment: spatial analyses of East Asia," Sustainability, vol. 11, no. 1, p. 13, 2019.

[6] M. D. Qamruzzaman and W. Jianguo, "Investigation of the asymmetric relationship between financial innovation, banking sector development, and economic growth," Quantitative Finance and Economics, vol. 2, no. 4, pp. 952-980, 2018.

[7] Z. Li, H. Dong, Z. Huang, and P. Failler, "Asymmetric effects on risks of virtual financial assets (VFAs) in different regimes: a case of bitcoin," Quantitative Finance and Economics, vol. 2, no. 4, pp. 860-883, 2018.

[8] C. Feng and M. Wang, "Journey for green development transformation of China's metal industry: a spatial econometric analysis," Journal of Cleaner Production, vol. 225, pp. 1105-1117, 2019.

[9] X. Zhu, Y. Chen, and C. Feng, "Green total factor productivity of China's mining and quarrying industry: a global data envelopment analysis," Resources Policy, vol. 57, pp. 1-9, 2018.

[10] M. E. Porter and C. V. D. Linde, "Toward a new conception of the environment-competitiveness relationship," Journal of Economic Perspectives, vol. 9, no. 4, pp. 97-118, 1995.

[11] B. Li and S. Wu, "Effects of local and civil environmental regulation on green total factor productivity in China: a spatial Durbin econometric analysis," Journal of Cleaner Production, vol. 153, pp. 342-353, 2017.

[12] J. Hu, Z. Wang, Y. Lian, and Q. Huang, "Environmental regulation, foreign direct investment and green technological progress-evidence from Chinese manufacturing industries," International Journal of Environmental Research and Public Health, vol. 15, no. 2, p. 221, 2018.

[13] C. Chen, Q. Lan, M. Gao, and Y. Sun, "Green total factor productivity growth and its determinants in China's industrial economy," Sustainability, vol. 10, no. 4, p. 1052, 2018.

[14] P. W. Kwakwa, H. Alhassan, and S. Aboagye, "Environmental Kuznets curve hypothesis in a financial development and natural resource extraction context: evidence from Tunisia," Quantitative Finance and Economics, vol. 2, no. 4, pp. 9811000, 2018.

[15] C. Li and X. Li, "Stochastic arrangement increasing risks in financial engineering and actuarial science-a review," Quantitative Finance and Economics, vol. 2, no. 1, pp. 190216, 2018.

[16] G. Liao and B. M. Drakeford, "An analysis of financial support, technological progress and energy efficiency: evidence from China," Green Finance, vol. 1, no. 2, pp. 174-187, 2019.

[17] J. Zhong, M. Wang, B. M. Drakeford, and T. Li, "Spillover effects between oil and natural gas prices: evidence from emerging and developed markets," Green Finance, vol. 1, no. 1, pp. 30-45, 2019.

[18] F. Islam, M. Shahbaz, A. U. Ahmed, and M. M. Alam, "Financial development and energy consumption nexus in Malaysia: a multivariate time series analysis," Economic Modelling, vol. 30, pp. 435-441, 2013.

[19] A. Jalil and M. Feridun, "The impact of growth, energy and financial development on the environment in China: a cointegration analysis," Energy Economics, vol. 33, no. 2, pp. 284-291, 2011.

[20] S. Farhani and I. Ozturk, "Causal relationship between $\mathrm{CO}_{2}$ emissions, real GDP, energy consumption, financial development, trade openness, and urbanization in Tunisia," Environmental Science and Pollution Research, vol. 22, no. 20, pp. 15663-15676, 2015.

[21] E. Dogan and B. Turkekul, " $\mathrm{CO}_{2}$ emissions, real output, energy consumption, trade, urbanization and financial development: testing the EKC hypothesis for the USA," Environmental Science and Pollution Research, vol. 23, no. 2, pp. 1203-1213, 2016.

[22] R. G. King and R. Levine, "Finance and growth: schumpeter might be right," The Quarterly Journal of Economics, vol. 108, no. 3, pp. 717-737, 1993.

[23] M. K. Mahalik, M. S. Babu, N. Loganathan, and M. Shahbaz, "Does financial development intensify energy consumption in Saudi Arabia?," Renewable and Sustainable Energy Reviews, vol. 75, pp. 1022-1034, 2017.

[24] S. Chen and J. Golley, “"Green" productivity growth in China's industrial economy," Energy Economics, vol. 44, pp. 89-98, 2014.

[25] G. Liu, B. Wang, and N. Zhang, "A coin has two sides: which one is driving China's green TFP growth?," Economic Systems, vol. 40, no. 3, pp. 481-498, 2016.

[26] C. Ye, C. Sun, and L. Chen, "New evidence for the impact of financial agglomeration on urbanization from a spatial econometrics analysis," Journal of Cleaner Production, vol. 200, pp. 65-73, 2018.

[27] G. Liao, D. Yao, and Z. Hu, "The spatial effect of the efficiency of regional financial resource allocation from the perspective of internet finance: evidence from Chinese provinces," Emerging Markets Finance and Trade, pp. 1-13, 2019.

[28] B. Zhu, J. He, and S. Zhai, "Does financial inclusion create a spatial spillover effect between regions? Evidence from China," Emerging Markets Finance and Trade, vol. 55, no. 5, pp. 980-997, 2019.

[29] X. Yu, M. Li, and S. Huang, "Financial functions and financial development in China: a spatial effect analysis," Emerging Markets Finance and Trade, vol. 53, no. 9, pp. 2052-2062, 2017. 
[30] A. Charnes, W. W. Cooper, and E. Rhodes, "Measuring the efficiency of decision making units," European Journal of Operational Research, vol. 2, no. 6, pp. 429-444, 1978.

[31] Z. Liu and L. Xin, "Has China's belt and road initiative promoted its green total factor productivity? - Evidence from primary provinces along the route," Energy Policy, vol. 129, pp. 360-369, 2019.

[32] D.-H. Oh, "A global Malmquist-Luenberger productivity index," Journal of Productivity Analysis, vol. 34, no. 3, pp. 183-197, 2010.

[33] H. Fukuyama and W. L. Weber, "A directional slacks-based measure of technical inefficiency," Socio-Economic Planning Sciences, vol. 43, no. 4, pp. 274-287, 2009.

[34] C. Feng, H. Zhang, and J.-B. Huang, "The approach to realizing the potential of emissions reduction in China: an implication from data envelopment analysis," Renewable and Sustainable Energy Reviews, vol. 71, pp. 859-872, 2017.

[35] J. Zhang, "Estimation of China's provincial capital stock (1952-2004) with applications," Journal of Chinese Economic and Business Studies, vol. 6, no. 2, pp. 177-196, 2008.

[36] Z. Li, G. Liao, Z. Wang, and Z. Huang, "Green loan and subsidy for promoting clean production innovation," Journal of Cleaner Production, vol. 187, pp. 421-431, 2018.

[37] Z. Huang, G. Liao, and Z. Li, "Loaning scale and government subsidy for promoting green innovation," Technological Forecasting and Social Change, vol. 144, pp. 148-156, 2019.

[38] J. P. Elhorst, "Applied spatial econometrics: raising the bar," Spatial Economic Analysis, vol. 5, no. 1, pp. 9-28, 2010.

[39] P. Valickova, T. Havranek, and R. Horvath, "Financial development and economic growth: a meta-analysis," Journal of Economic Surveys, vol. 29, no. 3, pp. 506-526, 2015.

[40] H. Dong, Y. Liu, and J. Chang, "The heterogeneous linkage of economic policy uncertainty and oil return risks," Green Finance, vol. 1, no. 1, pp. 46-66, 2019.

[41] Y.-J. Zhang, "The impact of financial development on carbon emissions: an empirical analysis in China," Energy Policy, vol. 39, no. 4, pp. 2197-2203, 2011.

[42] X. F. Pan, B. W. Ai, C. Y. Li, X. Y. Pan, and Y. B. Yan, "Dynamic relationship among environmental regulation, technological innovation and energy efficiency based on large scale provincial panel data in China," Technological Forecasting and Social Change, vol. 144, pp. 428-435, 2017.

[43] C. Feng, M. Wang, G.-C. Liu, and J.-B. Huang, "Green development performance and its influencing factors: a global perspective," Journal of Cleaner Production, vol. 144, pp. 323-333, 2017.

[44] X. Wang, C. Sun, S. Wang, Z. Zhang, and W. Zou, "Going Green or going away? A spatial empirical examination of the relationship between environmental regulations, biased technological progress, and green total factor productivity," International Journal of Environmental Research and Public Health, vol. 15, no. 9, p. 1917, 2018.

[45] D. Sornette, P. Cauwels, and G. Smilyanov, "Can we use volatility to diagnose financial bubbles? Lessons from 40 historical bubbles," Quantitative Finance and Economics, vol. 2, no. 1, pp. 486-590, 2018. 


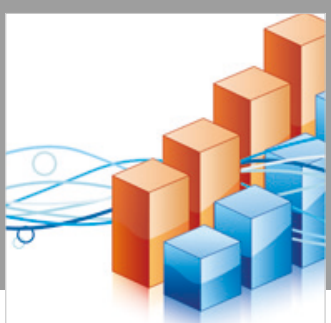

Advances in

Operations Research

\section{-n-m}
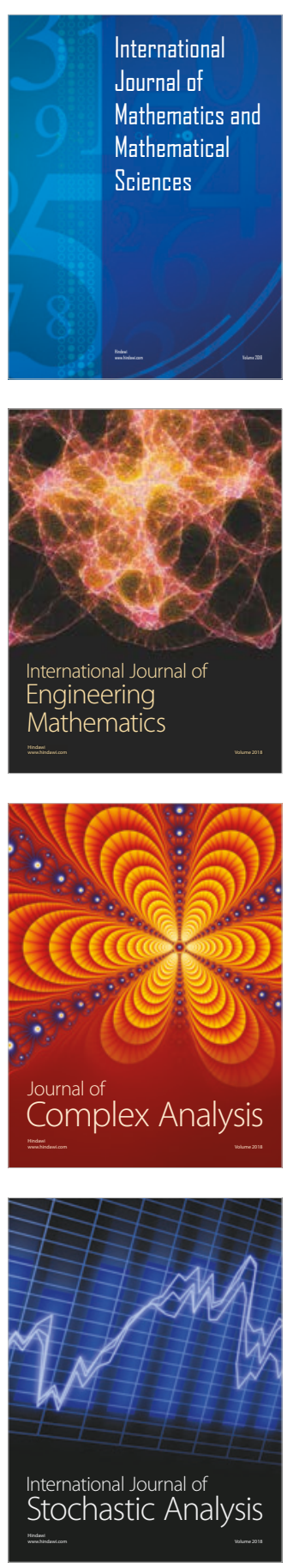
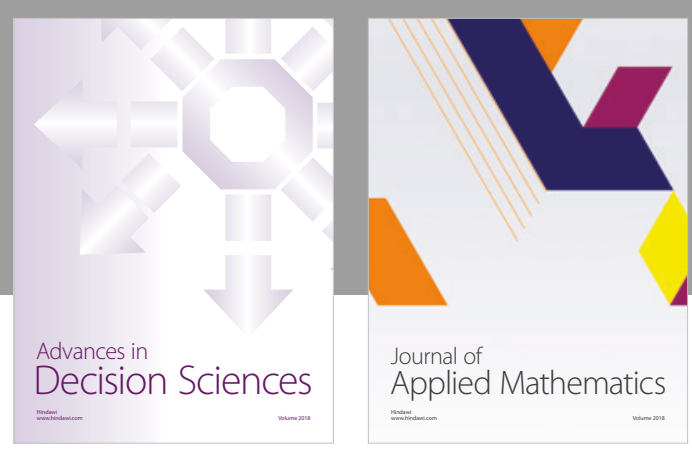

Journal of

Applied Mathematics
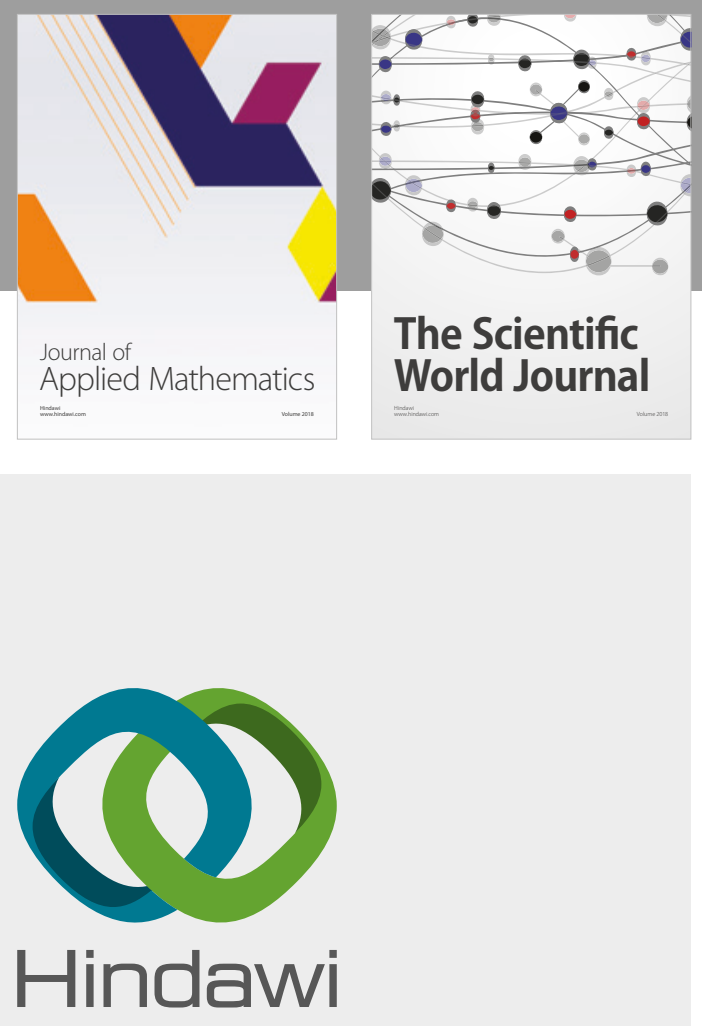

Submit your manuscripts at

www.hindawi.com

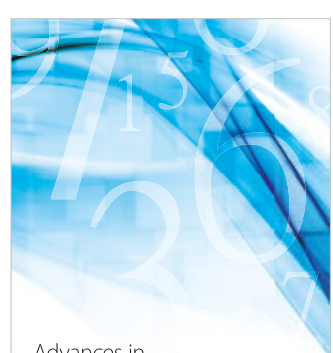

Advances in
Numerical Analysis
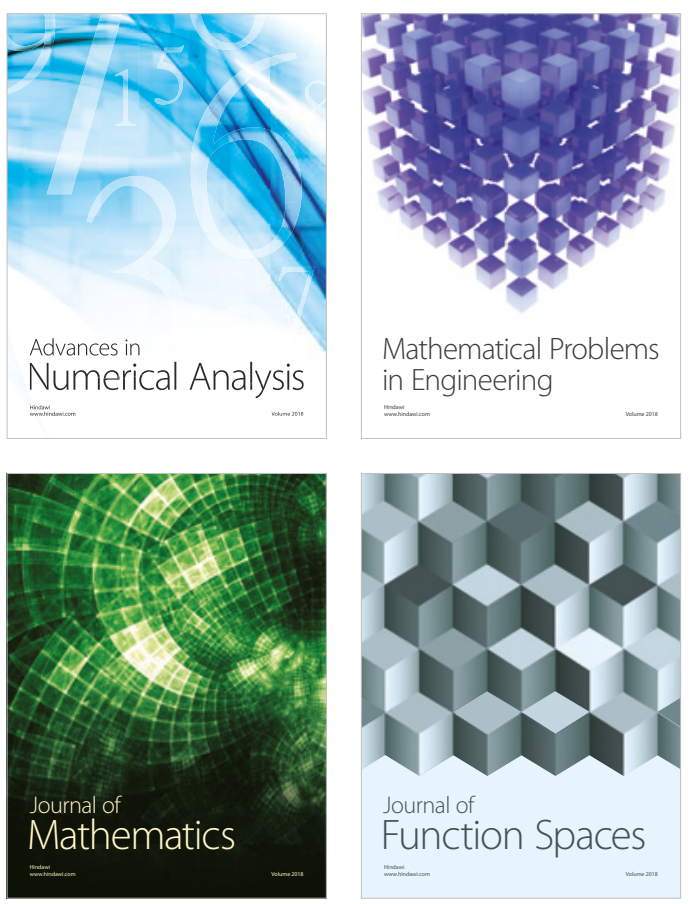

Mathematical Problems in Engineering

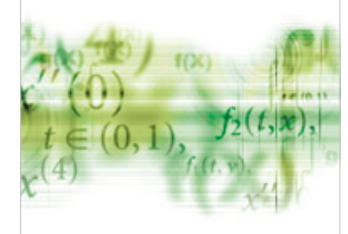

International Journal of

Differential Equations

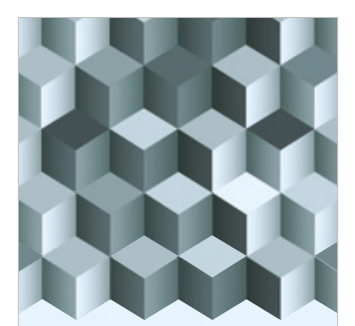

Journal of

Function Spaces



The Scientific

World Journal

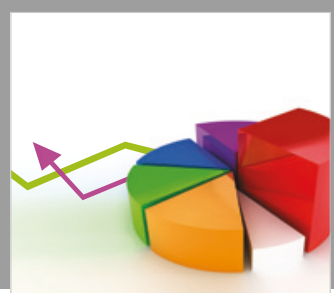

Journal of

Probability and Statistics
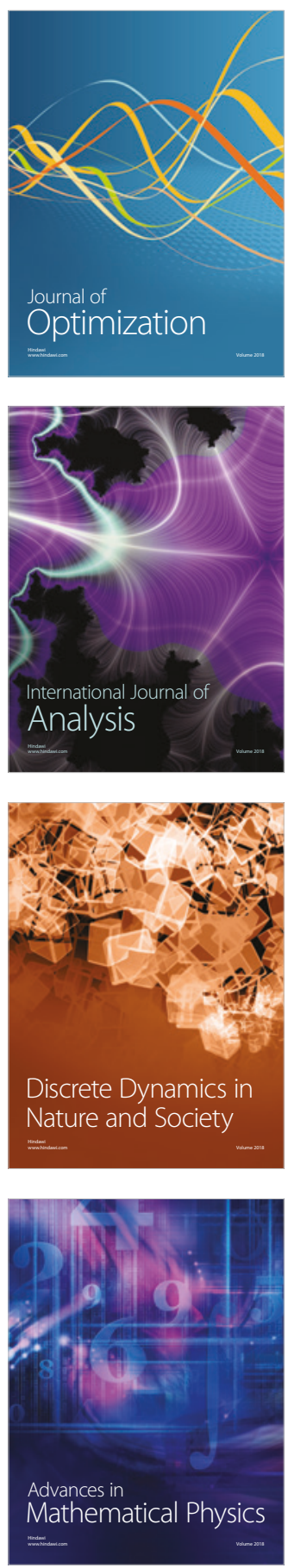